\title{
Perinephric Hematoma
}

National Cancer Institute

\section{Source}

National Cancer Institute. Perinephric Hematoma. NCI Thesaurus. Code C115786.

A collection of blood around the kidney. 